\title{
Bone Resorption around Self-Tapping Implants in Bone Density Type I-II: 3-Years Results of a Prospective Clinical Study
}

\section{Hadi Gholami ${ }^{1, *}$, Regina Mericske-Stern², Peter Jöhren ${ }^{3}$, and Norbert Enkling ${ }^{4,5}$}

${ }^{1}$ Assistant Professor, Department of Prosthodontics, Tufts University, School of Dental Medicine, Boston-MA, USA

${ }^{2}$ Professor emeritus, School of Dental Medicine, University of Bern, Switzerland

${ }^{3}$ Associate Professor, Department of Oral Surgery, University of Witten/Herdecke, Germany

${ }^{4}$ Associate Professor, Department of Prosthodontics, Preclinical Education and Dental Material Science, University of Bonn, Germany

${ }^{5}$ Department of Reconstructive Dentistry and Gerodontology, School of Dental Medicine, University of Bern, Switzerland

*Corresponding author: Hadi Gholami, Assistant Professor, Department of Prosthodontics, Tufts University, School of Dental Medicine, Boston-MA, USA, Tel: +1 (617)636-6930; E-mail: hadi.gholami@tufts.edu

Received: 24 Feb, 2020 | Accepted: 12 Mar, 2020 | Published: 17 Mar, 2020

Citation: Gholami H, Mericske-Stern R, Jöhren P, Enkling N (2020) Bone Resorption around Self-Tapping Implants in Bone Density Type I-II: 3-Years Results of a Prospective Clinical Study. Int J Dent Oral Health 6(3): dx.doi.org/10.16966/2378-7090.320

Copyright: ( 2020 Gholami H, et al. This is an open-access article distributed under the terms of the Creative Commons Attribution License, which permits unrestricted use, distribution, and reproduction in any medium, provided the original author and source are credited.

\section{Abstract}

Objectives: Placing self-tapping implants in High-density Bone (HDB) could increase the cortical stress during implant insertion enhancing periimplant bone resorption. There is a general consensus to avoid self-tapping implants use in HDB. This study assesses the success rate and clinical outcome of self-tapping implants in dense bone.

Materials and Methods: This prospective single-blind controlled clinical trial was conducted on 26 patients who received 2-5 implants in the posterior mandible. Drilling protocol was adapted with the quality of existing bone. Patients were examined at the time of surgery (T1), 3 months post-operation (T2), 4 months post-surgery (T3), 12 months post-surgery (T4), 25 months post-surgery (T5) and 38 months post-operation (T6). Standardized radiographs were obtained at all time points. Three observers measured the crestal bone level changes. Data was analyzed using nonparametric statistics.

Results: The success rate was $100 \% 3$ years after placing self-tapping implants in HDB. Mean bone loss of $-0.56 \mathrm{~mm}(\mathrm{Cl} 95 \%-0.69 ;-0.42)$ was observed from the time of surgery to the delivery of the crown. After the healing period during functional loading (at 4 to 38 months) there was only a mean bone level alteration of less than $-0.04 \mathrm{~mm}$ per year.

Conclusion: In this clinical study, all 90 self-tapping implants that have been placed in type I and type II bone were successful 3 years after placement, with minimal crestal bone level changes.

Clinical relevance: Self-tapping implants can be successfully placed in HDB. However, clinicians must be aware of using a bone quality adapted drilling protocol.

Keywords: Bone level; Bone loss; Dental implants; Implant design; Implant success; High-density bone

\section{Introduction}

Osseointegrated implants are now successfully used to restore function in fully or partially edentulous patients. Use of endosseous dental implants for the replacement of missing teeth has become increasingly popular during the past 30 years. Implants placed in bone of optimal quality and quantities have led to excellent results with successful clinical outcomes [1]. However, the long-term success is less predictable in cases where the implant is placed in bone of poor quality (i.e. soft bone) [1] or quantity (i.e. limited bone volume) [2]. Bone mineral density can greatly affect screw performance [3] and plays an important role in subsequent success or failure of implant treatment. Density (quality) of bone structure in the implant placement area varies from site to site and person to person.
Dental implants placed in the mandible have been shown to have a higher survival rate compared to maxillary implants. The anterior region of the mandible carries the greatest survival rate of implants due to having the densest bone. Posterior region of the maxilla has the highest rate of implant failure attributed to the insufficient bone volume and/or density [4]. Therefore, evaluation of bone structure prior to implant placement is critical to its survival.

Several methods have been proposed for clinical evaluation of bone quality either prior to or during endosseous implant placement by tactile perception of site-preparation [5]. For classification of quantity and quality of alveolar bone, Lekholm $U$ and Zarb GA [6] radiographically categorized bone density into 4 groups based on the volume of cortical bone compared to trabecular bone. The 
authors classified type 1 bone when "the entire jaw is comprised of homogenous compact bone;" type 2 bone when "a thick layer of compact bone is present surrounding a core of dense trabecular bone;" type 3 bone when "a thin layer of cortical bone surrounds a core of dense trabecular bone;" and type 4 when "a thin layer of cortical bone surrounds a core of low density trabecular bone" [7].

Another classification was offered by Misch CE [8] who correlated the bone density to the bone clinical hardness as subjectively perceived during the drilling procedure prior to implant insertion. D1 bone is "oak or maple-like", and D2 is "similar to spruce or white pine wood". According to Misch's classification, D1 and D2 bones are usually found in the mandible and the anterior maxilla. Truhlar RS, et al. [9] modified the classification of Leckholm U and Zarb GA [6] in their study by adding the tactile sensation during drilling. They also found the densest bone in the anterior region of mandible followed by the posterior mandible, anterior maxilla, and posterior maxilla [9].

The configuration and design of implant body (both macro-design and micro-design) is another parameter that can affect implant success or failure [10]. Self-tapping implants were first introduced to the market in 1983. This modification of implant design has eliminated the need for tapping during implant insertion. It has been demonstrated by Olsson M, et al. [11] and Ivanoff CJ, et al. [12] that the primary stability of implants has improved with self-tapping implants especially in highly cancellous low density bone since the implant compresses the surrounding spongy bone and increases the density of peri-implant bone. However, over compression of the bone structure adjacent to the implant insertion site can have a negative effect leading to implant failure, though more clinical data and studies are needed on this subject matter. Some studies have shown that implant loosening can be caused by formation of collagen-rich connective tissue capsule around the implant due to higher pressure while drilling [13]. The same may occur when self-tapping implants are placed in high density bone that is mainly comprised of cortical bone as this type of bone is more resistant to deformation due to having higher modulus of elasticity and low blood supply [14]. These characteristics decrease the ability of load distribution and increase the susceptibility to bone necrosis of the dense cortical bone compared to trabecular bone as the result of application of excessive torque at the time of implant placement [15]. Unintentionally high or excessive torque applied when inserting the implant can result in excessive compression of the cortical bone causing microdamage, which is a permanent deformation of the microstructure of loaded cortical bone in the form of fatigue and creep. These microdamages can manifest histologically as microcracks, which are discontinuities of the calciumrich bone matrix surrounding implants [15]. According to some orthopedic studies, microcracks are irreversible and can subsequently result in loosening or failure of implants [16].

Placement of self-tapping implants in compact bone also has a risk of bone necrosis due to excess heat generation [17]. Necrosis of the bone contributes to osteolysis around the implant resulting in loss of stability. It has been reported that impaired bone generation occurs when the healing process is compromised as the bone is exposed to $47^{\circ} \mathrm{C}$ heat for 5 minutes or $50^{\circ} \mathrm{C}$ heat for 1 minute [18]. This unwanted temperature rise during implantation is greater in compact bones [19].

Efficacy of self-tapping implants in soft bone quality has been very ellw documented while limited evidence is available on the efficacy of self-tapping implants in hard bone quality [10]. The present study sought to assess the success rate and clinical outcome of self-tapping implants in dense bone.

\section{Materials and Method}

\section{Study design}

This prospective single blind controlled clinical trial was conducted on 26 subjects according to sample size calculations. A total of 2-5 implants were inserted for each patient in the posterior mandible. Patients were evaluated and examined at the time of surgery (T1 or baseline), at second-stage surgery which was 3 months post-operation (T2), at the time of suprastructure placement which was 4 months post-surgery (T3), at first recall which was 12 months post-surgery (T4), at second recall (T5) which was 25 months post-surgery and at third recall (T6) which was 38 months post-operation. Standardized radiographs were obtained at all time-points.

\section{Understudy population}

Twenty-six patients (13 females, 13 males with a mean age of 50.7 \pm 10.5 years) presenting to the Dental Clinic Bochum/University of Witten/Herdecke, Germany were enrolled in this study. Patients with good general health and no systemic disease, no drug intake, no pregnancy or nursing, adequate bone quantity to accommodate 9.5 $\mathrm{mm}$ length and $4 \mathrm{~mm}$ diameter implants, $4 \mathrm{~mm}$ of keratinized mucosa in the buccolingual aspects of the implant site and medium or thick soft tissue biotype (i.e. crestal mucosa thickness $\geq 2 \mathrm{~mm}$ according to $\mathrm{Fu} \mathrm{JH}$, et al. [20]) were included. To assess the adequacy of bone quantity for implant placement, two observers separately assessed bone dimensions and expressed their opinion regarding the adequacy or inadequacy of the residual bone for implant placement. The two observers agreed on this topic in all cases and the Kappa coefficient was calculated to be 1 . The width of alveolar process was measured with the bone mapping technique; a process that confirms adequate dimension of bone exists prior to implant placement. Bone mapping quantifies the thickness of the ridge ( $\mathrm{mm}$ scale) throughout the implant site by taking several measurements of the ridge crest and 7 $\mathrm{mm}$ vertically to that point [21]. The teeth had to be extracted at least 6 months earlier and implant site had to be free from infection and extraction residue.

Patients with compromised medical health or those with poor compliance to treatment, previous tumors, chronic bone disease or undergoing irradiation of the planned treatment site were excluded from this study. Those undergoing augmentation procedures such as bone grafting or guided bone regeneration were also excluded.

\section{Implants}

SICace implant system (SIC-Invent, Basel, Switzerland) was used in this study. This implant system has an internal hex connection with an interlocking clearance fit [22] and a medium-rough sand-blasted, acid-etched surface including the implant collar. The implants used had a $9.5 \mathrm{~mm}$ height and a $4 \mathrm{~mm}$ diameter. The abutment platform was shifted from $4-3.3 \mathrm{~mm}$ diameter providing a $0.35 \mathrm{~mm}$ circular step (Figure 1). The circular step surface was machined. The diameter of the cover screws was $3.3 \mathrm{~mm}$. Thus, the cover screw had a platformswitched outline.

\section{Radiographic assessment}

Radiographic follow-up of patients was carried out at all timepoints by taking 6 standardized digital panoramic images (OPGs) using Promax PRX232574 (Planmeca, Helsinki, Finland). For the purpose of standardization, the mandible of patients was fixed with a custom-made bite splint and the unit was individually adjusted based on each patient's position. DIMAXIS software 4.3.1 (Planmeca) with a measuring precision of $0.01 \mathrm{~mm}$ was used for radiographic 


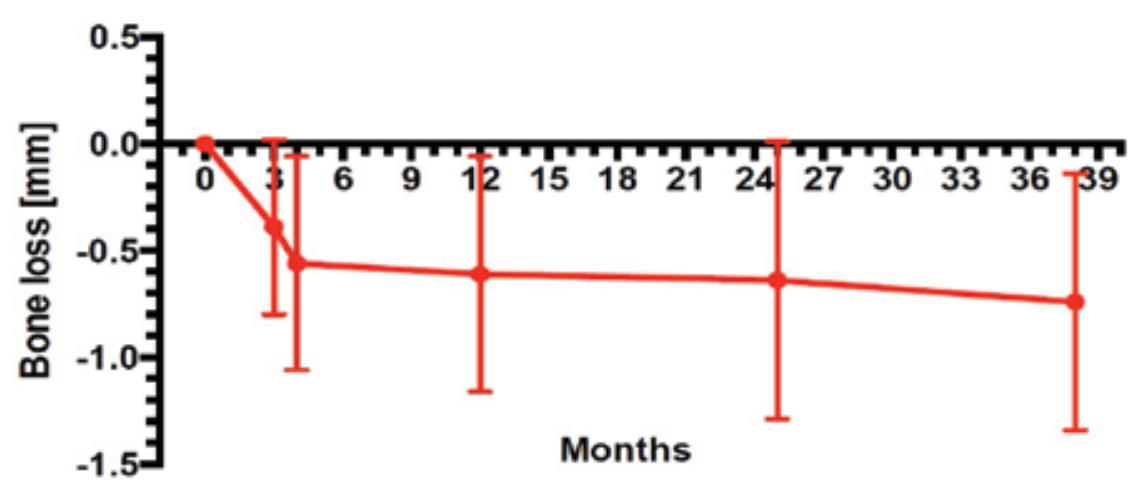

Figure 1: Means \pm SD of the alteration of vertical implant bone level (IBL).

measurement and analyses. The areas of interest on the radiographs were magnified with $20 \times$ magnification using the software tools and bone height measurements were calibrated at $9.5 \mathrm{~mm}$ implant length. Crestal bone level was measured at mesial and distal surfaces of implants. Implant shoulder was considered as the Reference Point (RP) for these measurements. The other units measured were as follows: IBL (vertical implant bone level with the micro-gap as the RP), which is defined as the vertical distance between the micro-gap and the most coronal bone to implant contact and GBL as the general horizontal bone level (Figures 2 and Figure 3). Changes of the crestal bone level over time are expressed as differences of the measured values: $\triangle \mathrm{IBL}$ and $\triangle$ GBL. For statistical analyses, the mean values of mesial and distal measurements were used. Three calibrated dentists experienced in oral radiology independently performed the radiographic assessment. If the differences in the measurements by the three examiners were $0.1 \mathrm{~mm}$ or less, the mean of the three measurements was used. If the differences were more than $0.1 \mathrm{~mm}$, the three examiners were asked to re-analyze the specific implant together to reach a consensus.

\section{Clinical procedure}

Bone shape and density were determined based on preoperative radiographs. Bone density was classified using the Lekholm $U$ and Zarb GA classification system described in 1985 [6].

Local anesthesia was induced by injection of the anesthetic agent (Ultracain UDS forte, Epinephrine 1:100,000, Sanofi-Aventis, Paris, France). A crestal incision was made, followed by the elevation of a full-thickness flap exposing the surgical site. According to the manufacturer's instructions and presurgical assessment, and on perception of bone density, the drilling protocol was modulated to obtain the so-called adapted drilling. The tapping drill was used for placement of implants in bone with type 1 density (approximately $40 \%)$. The tapping drill was not used for type 2 bones. Implants were aligned at bone level with a minimum distance of $3 \mathrm{~mm}$ from one another. Surgical re-contouring of the alveolar bone was not carried out and Implant insertion torque did not exceed $50 \mathrm{Ncm}$. The implants were left submerged for a 3 month healing period. After the placement of implants and the second-stage surgery the patients were asked to rinse their mouths with $0.2 \%$ chlorhexidinegluconate mouthwash (Meridolperio, GABA, Therwil, $\mathrm{CH}$ ) for 1 minute twice a day for 1 week until the sutures were removed. Mechanical cleaning at the implant sites was not allowed for patients 6 weeks after implant placement and 2 weeks after the second stage surgery. Appointments were scheduled at 1 and 2 months after surgery in order to control wound healing, gingival health (full-mouth Sulcular Bleeding Index (SBI) [23]) and oral hygiene (full-mouth Plaque Index (PI) [24]). Submerged implant was re-entered by raising a small full-thickness flap 3 months after the implant placement. Impressions were taken 2 weeks later followed by the try-in of the casted crown frameworks after 1 week. Seven days later (4 months after implant surgery), full ceramic-veneered, casted single crowns were fabricated, SICace standard titanium abutments (SIC No. 936163) were tightened on the implants using $20 \mathrm{Ncm}$ force. Crowns were mounted on the abutments with temporary cement. Oral hygiene of patients was closely monitored at all time-points as well as oral health and implant status. Oral hygiene of patients was also reinforced by hygiene re-instruction, or professional plaque control if necessary every 6 months.

The criteria for implant success used in this study were those described by Albrektsson T, et al. [25]. According to them, a successful implant is characterized by:

1. No radiolucency around the implant at the 1 year follow-up.

2. Bone resorption within the limits suggested by Albrektsson $\mathrm{T}$ and colleagues [25].

3. No mobility of the individual implant and no signs of infection, pain or any ongoing pathology.

\section{Statistical Analysis}

The primary outcome variable was changed IBL between BL and 3 years after surgery. The primary hypothesis of this study was that IBL changes were less than $1.1 \mathrm{~mm}$, i.e. significantly less $(0.4 \mathrm{~mm})$ [26] than success criterion $(1.5 \mathrm{~mm})$ [27] when using self-tapping implants in both bone type I and II. The secondary hypothesis was that bone loss is not significantly different in type I bone compared to type II and is time-dependent. A global test of the dependence of the IBL value on time and bone hardness using the non-parametric model of Brunner E, et al. [28] was performed in a descriptive manner. Sample-size was calculated as 24 patients using $G^{\star}$ POWER 3 [29] for achieving a power of $80 \%$. Considering the possible dropouts, 26 subjects were included in the study. This estimate was based on a two-tailed test of matched pairs conducted at the $5 \%$ level of significance.

Based on the available literature [30], a bone loss of $0.7 \mathrm{~mm}$ with a standard deviation of 0.75 is usually expected after 3 years of having implants in function. The SAS 9.2 software (SAS Institute, Heidelberg, Germany) was used. Graphs were prepared with the PRISM 4 software (GraphPad Software Firma, La Jolla,CA, USA). 

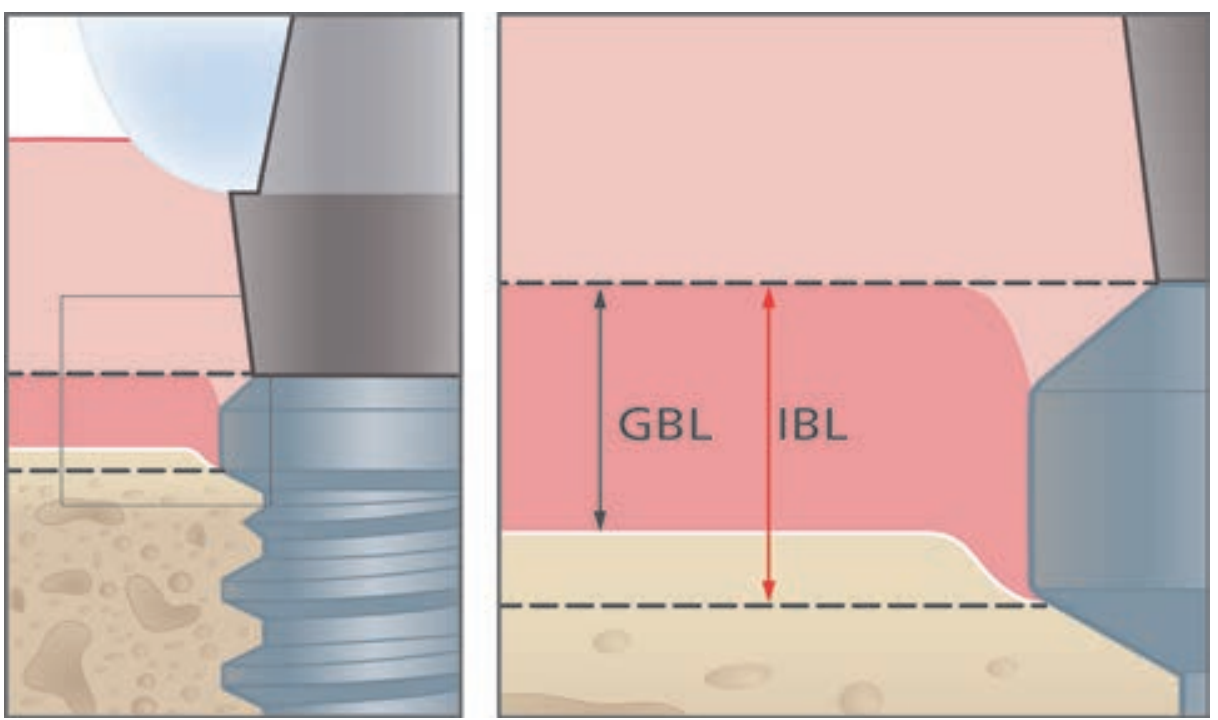

Figure 2: The measured distances at the radiographs: The red area demonstrates the bone-level alteration since baseline (implant insertion operation). IBL, vertical bone level at the implant (reference point: implant platform); GBL, general horizontal bone level (reference point: implant platform).
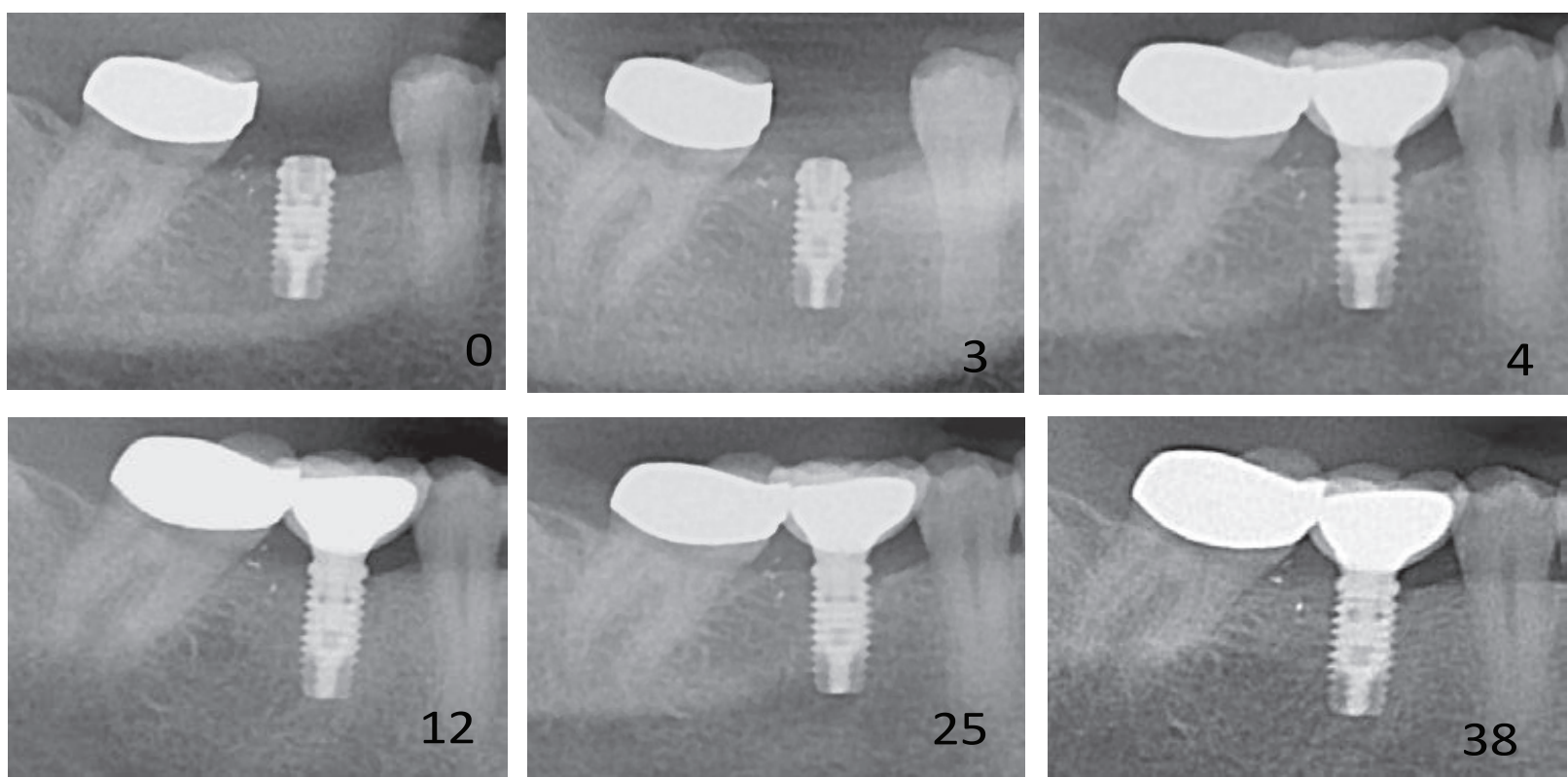

Figure 3: Examples of radiographs taken from standardized panoramic images indicating implant placement (baseline) and 3,4,12,25, and 38 months postoperatively.

\section{Results}

After the healing period, all inserted implants were clinically stable and no implant failure or patient drop out were recorded during the follow-up period; thus, the survival rate was $100 \%$. The peri-implant condition was healthy in all subjects. There was no bleeding on probing around the implants and patients had favourable oral hygiene. After delivery of the crowns, good oral hygiene was observed with a plaque index of 0.52 (CI 95\% 0.46; 0.58) and bleeding index of 0.37 (CI 95\% 0.32; 0.42) (Table 1). No significant changes in probing depth measurements around the implants were observed. The mean probing depth was 2.39 (CI 95\% 2.34; 2.44) (Table 2). Minimal bone loss of $-0.56 \mathrm{~mm}$ (CI $95 \%-0.69 ;-0.42)$ was observed from the time of surgery to the delivery of the crown. During the 34 months after loading, the additional bone loss was averagely $-0.08 \mathrm{~mm}$ (CI $95 \%-0.20$; 0.04 ) (Figure 2). Table 3 shows bone level changes $(\mathrm{mm})$ at all time-points. A negative value at the Y-axis indicates that the most coronal bone to implant contact was more apical than the implant shoulder and vice versa. 
Table 1: Full-Mouth Plaque Index (Silness J and Loe H [24]) and Sulcular Bleeding Index (Muhlemann HR and Son S [23]).

\begin{tabular}{|c|c|c|c|c|}
\hline $\begin{array}{l}\text { Index: Months } \\
\text { Postoperatively }\end{array}$ & Mean & SD & Minimum & Maximum \\
\hline \multicolumn{5}{|c|}{ Plaque Index } \\
\hline 0 & 0.55 & 0.32 & 0.18 & 1.38 \\
\hline 3 & 0.52 & 0.33 & 0.14 & 1.38 \\
\hline 4 & 0.45 & 0.29 & 0.07 & 0.97 \\
\hline 8 & 0.28 & 0.21 & 0 & 0.73 \\
\hline 12 & 0.36 & 0.23 & 0 & 0.86 \\
\hline 25 & 0.39 & 0.18 & 0.02 & 0.72 \\
\hline 38 & 0.35 & 0.20 & 0.04 & 0.69 \\
\hline 0 & 0.55 & 0.32 & 0.18 & 1.38 \\
\hline \multicolumn{5}{|c|}{ Bleeding Index } \\
\hline 0 & 0.34 & 0.27 & 0 & 0.90 \\
\hline 3 & 0.52 & 0.40 & 0 & 1.00 \\
\hline 4 & 0.32 & 0.24 & 0 & 0.90 \\
\hline 8 & 0.21 & 0.19 & 0 & 0.80 \\
\hline 12 & 0.25 & 0.24 & 0 & 0.83 \\
\hline 25 & 0.31 & 0.25 & 0 & 0.90 \\
\hline 38 & 0.29 & 0.30 & 0 & 0.88 \\
\hline
\end{tabular}

SD: Standard Deviation

Table 2: Mean probing depth (PD) at studied implants.

\begin{tabular}{|c|c|c|c|c|}
\hline $\begin{array}{c}\text { Time (months } \\
\text { post OP) }\end{array}$ & Mean & SD & Minimum & Maximum \\
\hline 8 & 2.35 & 0.42 & 1.50 & 3.00 \\
\hline 12 & 2.39 & 0.50 & 1.25 & 3.00 \\
\hline 25 & 2.82 & 0.52 & 1.75 & 3.50 \\
\hline 38 & 2.74 & 0.53 & 1.75 & 3.50 \\
\hline
\end{tabular}

SD: Standard Deviation

After the healing period during functional loading (at 4 to 38 months) there was a minimal mean bone level alteration of $-0.04 \mathrm{~mm}$ per year.

Technical complications did not occur, but 2 crowns exhibited minimal chipping of the ceramic veneering.

The primary hypothesis was accepted $(\mathrm{P}<0.001)$ (post-hoc power: 99.4\%): On average, the STI in HDB showed a peri-implant crestal bone loss that was statistically and clinically reduced compared with the accepted implant-success-criteria.

The secondary hypothesis was also accepted, as bone level alteration depended on time $(\mathrm{P}<0.001)$ but not on bone-type $(\mathrm{P}=0.348)$ and not on the interaction of time and bone-type $(\mathrm{P}=0.945)$.

\section{Discussion}

In literature, early implant success is defined as successful outcome of implants for 1 to 3 years. Based on this statement, we may state that our understudy implants fell into the category of early implant success [31].

Dental implants generally have a high survival rate: on average, only $2.5 \%$ of all implants placed are lost before loading. After loading, the failure rate is $0.5-1.3 \%$ per year [32]. Albrektsson T, et al. [25] proposed a widely used criterion for evaluation of the success of dental implants.
One criterion states that the in the first year of service, crestal bone resorption should be less than $1.5 \mathrm{~mm}$ and the bone loss should not exceed $0.2 \mathrm{~mm}$ annually thereafter. Astrand P, et al. [26] considered a true difference of $0.4 \mathrm{~mm}$ to be of clinical importance. In our study, we added this measure together to that of Albrektss on success criterion to determine whether the successful outcome of self-taping implants in high-mass bone is clinically substantial. Radiographic crestal bone loss less than $2.0 \mathrm{~mm}$ in comparison with the implant insertion surgery is another criterion suggested by Misch CE, et al. [31]. However, due to the advancements in implantology during the recent years, this rate has further decreased for different implant systems. A metaanalysis [33] reported marginal bone loss of 0.24 for Astra Tech, 0.75 for Branemark and 0.48 for Straumann implant systems at 5 years of loading. These changes between implant systems may be attributed to different thread design.

On the other hand, bone loss following implant insertion is associated with several factors such as $\triangle \mathrm{GBL}$; which was 0.26 in this study; $50 \%$ vertical bone loss value was attributed to GBL because flap elevation for implant placement or at the second stage surgery can lead to bone resorption [34].

Friberg B, et al. [33] reported a $100 \%$ success rate for self-tapping implants placed in the mandible. Widmark G, et al. [35] also reported a high one-year success rate (98.4\%) for MK III self-tapping implants. Their results were similar to our results in this regard, but they did not mention the type of bone in which self-tapping implants were placed.

The design of self-tapping implants can potentially increase the primary stability due its compressive effect on bone though this rationale is still controversial. Unlike Al-Nawas B, et al. [36] and Toyoshima $\mathrm{T}$, et al. [37] who reported higher insertion torque and Implant Stability Quotient (ISQ) values for self-tapping implants compared to non self-tapping implants and considered them as a good choice for use in low-density bone [37], others like Kim DR, et al. [38] and Rabel A, et al. [39] reported lower primary stability in selftapping implants. According to Kim DR, et al. [38], implants with nonself-cutting blades cause a lateral compression with higher contact surface area and therefore have a better primary stability. However, they used a simulated low-density bone model instead of natural bone in their study, which may have affected the results. Yoon HG, et al. [40] evaluated self-tapping implants in bone qualities similar to what was evaluated in the present study (type 1 and type 2 bones). They noticed that the primary implant stability had a direct and positive correlation with the density of surrounding bone. In general, the load transfer from the implant to the surrounding bone structure depends on bone-implant interface, which is influenced by implant design as well as quality and quantity of the bone structure. Yet this compression is not always in favor of implant success especially when it enhances the cortical stress. Different classifications describing "bone quality" or "bone density" have been proposed. The most widely cited classification of bone quality was established by Lekholm $U$ and Zarb GA [6] and was based on preoperative radiographic assessment of cortical versus trabecular bone. Type I and II bones correspond to thicker cortical bones. Kitagawa T, et al. [41] conducted stress analysis of bone around implants and concluded that the highest (15.7 MPa) and lowest von Mises equivalent stress $(0.02 \mathrm{MPa})$ were applied to the cortical and cancellous bones, respectively. According to them, von Mises equivalent stress depends on the thickness of cortical bone which varies for different bone types [42,43]. In another study by Quaresma SE, et al. [42] the cortical bone that was in direct contact with implants, the alveolar crest and the apical region showed a greater von Mises stresses when compared to trabecular bone. Papavasiliou 
Table 3: Mean bone level changes $(\mathrm{mm})$ at all time points after surgery.

\begin{tabular}{|c|c|c|c|c|c|c|c|c|c|c|c|c|c|}
\hline \multirow[b]{2}{*}{ Time } & \multirow[b]{2}{*}{$\begin{array}{l}\text { Measured } \\
\text { Distance }\end{array}$} & \multicolumn{4}{|c|}{ All Implants ( $\mathrm{N}=96)$} & \multicolumn{4}{|c|}{ Bone Type I ( $N=45)$} & \multicolumn{4}{|c|}{ Bone Type II (N=51) } \\
\hline & & Mean & SD & Median & $\begin{array}{l}95 \% \mathrm{Cl} \text { for } \\
\text { the median }\end{array}$ & Mean & SD & Median & $\begin{array}{l}95 \% \mathrm{Cl} \text { for } \\
\text { the median }\end{array}$ & Mean & SD & Median & $\begin{array}{l}95 \% \mathrm{Cl} \text { for } \\
\text { the median }\end{array}$ \\
\hline \multirow[t]{2}{*}{3 Months T1 } & $\Delta \mathrm{IBL}$ & -0.39 & 0.41 & -0.37 & $-0.55 ;-0.10$ & -0.45 & 0.52 & -0.45 & $-0.61 ; 0.00$ & -0.32 & 0.43 & -0.30 & $-0.45 ;-0.10$ \\
\hline & $\Delta \mathrm{GBL}$ & -0.26 & 0.38 & -0.27 & $-0.38 ; 0.00$ & -0.3 & 0.21 & 0.20 & $-0.05 ; 0.00$ & -0.16 & 0.33 & -0.17 & $-0.38 ; 0.00$ \\
\hline \multirow[t]{2}{*}{4 Months T2 } & $\Delta \mathrm{IBL}$ & -0.56 & 0.50 & -0.57 & $-0.70 ;-0.20$ & -0.61 & 0.42 & -0.59 & $-0.69 ;-0.21$ & -0.42 & 0.55 & -0.39 & $-0.80 ;-0.20$ \\
\hline & $\Delta \mathrm{GBL}$ & -0.24 & 0.46 & -0.11 & $-0.27 ; 0.00$ & -0.27 & 0.25 & -0.21 & $-0.29 ; 0.00$ & -0.20 & 0.46 & -0.10 & $-0.27 ;-0.05$ \\
\hline \multirow{2}{*}{$\begin{array}{c}12 \text { Months } \\
\text { T4 }\end{array}$} & $\triangle \mathrm{IBL}$ & -0.61 & 0.55 & -0.63 & $-0.92 ;-0.43$ & -0.68 & 0.35 & -0.61 & $-0.90 ;-0.28$ & -0.57 & 0.55 & -0.48 & $-0.82 ;-0.23$ \\
\hline & $\Delta \mathrm{GBL}$ & -0.28 & 0.47 & -0.18 & $-0.37 ; 0.00$ & -0.34 & 0.35 & -0.30 & $-0.50 ; 0.00$ & -0.19 & 0.47 & -0.18 & $-0.37 ; 0.00$ \\
\hline \multirow{2}{*}{$\begin{array}{c}25 \text { Months } \\
\text { T5 }\end{array}$} & $\Delta \mathrm{IBL}$ & -0.64 & 0.65 & -0.64 & $-0.77 ;-0.51$ & -0.72 & 0.35 & -0.73 & $-0.82 ;-0.45$ & -0.57 & 0.80 & -0.60 & $-0.69 ;-0.40$ \\
\hline & $\Delta \mathrm{GBL}$ & -0.26 & 0.63 & -0.28 & $-0.41 ;-0.10$ & -0.33 & 0.45 & -0.35 & $-0.50 ; 0.00$ & -0.21 & 0.72 & -0.19 & $-0.42 ;-0.10$ \\
\hline \multirow{2}{*}{$\begin{array}{c}38 \text { Months } \\
\text { T6 }\end{array}$} & $\Delta \mathrm{IBL}$ & -0.74 & 0.60 & -0.70 & $-1.02 ;-0.50$ & -0.81 & 0.43 & -0.78 & $-0.87 ;-0.40$ & -0.66 & 0.58 & -0.63 & $-0.19 ;-0.29$ \\
\hline & $\Delta \mathrm{GBL}$ & -0.36 & 0.56 & -0.32 & $-0.61 ;-0.15$ & -0.36 & 0.45 & -0.35 & $-0.65 ;-0.15$ & -0.32 & 0.50 & -0.32 & $-0.45 ;-0.20$ \\
\hline
\end{tabular}

G, et al., [43] evaluated clinical cases of IMZ implants placed in edentulous mandibles; however, the implants they used were not selftapping. They reported the highest amount of stress concentration in the cortical bone [43]. Several researchers have extensively evaluated bone necrosis as the result of the high strain exerted to the bone during surgery [44,45]. Adell R, et al. [46] was the first to suspect bone compression necrosis as the result of implant bed preparation. Another report was done in 1998 by Piattelli A, et al. [45], describing implant failure to be caused by compression necrosis. The authors believed the failure to be the result of overheating of bone during drilling and excessive torque leading to compression of bone chips at the apical region of the implant. Another parameter that must be considered is that the crestal bone is extremely susceptible to early bone loss (1.2 $\mathrm{mm}$ averagely) due to having the lowest vascularity and minimal resistance against shear forces [46]. Overall, application of excessive torque during the implant placement into dense bone can lead over-compression of adjacent bone structure and higher the risk of failure to several folds.

It must be noted that all these can be avoided. When the implant insertion torque stays within the limits of $30-40 \mathrm{~N} / \mathrm{cm}$, the risk of bone over-heating can be reduced to a great extent [47]. Atieh MA, et al. [48] stated that the use of $70 \mathrm{~N} / \mathrm{cm}$ or more implant insertion torque substantially increases the stress on the cortical bone. They recommended applying moderate insertion torque value $(32-50 \mathrm{~N} /$ $\mathrm{cm})$ to minimize the risk of early implant failure. As mentioned earlier, we did not exceed the implant insertion torque of $50 \mathrm{~N} / \mathrm{cm}$, which may have contributed to our favorable results. Moreover, the same drilling protocol was not applied to all the cases in our study. Other authors have modified Lekholm's classification; Misch CE [8] introduced a classification of bone density based on tactile feedback during drilling. In order to be more precise and to follow the drilling instructions of the manufacturer, the two classifications were combined in our study. Firstly, the high-mass bones were found radiographically and then they were assorted once again during the osteotomy according to Misch's classification. Secondly, type 1 bone was used to tap drill in order to decrease the likelihood of over-heating or over-loading of the bone.
Several other factors can also affect cortical stress. The design of section containing the implant neck and abutment connection may influence the amount of stress exerted on the peri-implant cortical bone. Changes in peri-implant cortical bone are also caused by physical stresses to the neck area of the bone-implant interface [48].

Cortical stress may shows its effects at a later time as some failures like marginal bone loss and osseo-disintegration due to the concentration of stress at the site occur after loading of implants.

Such failures occur as the result of difference in rigidity of the implant and surrounding bone, which leads to transmission of stress to the failure site [43]. After 3 years of follow-up, such influences did not significantly affect our results.

The results of the3-year follow-up support both hypotheses of this study.

\section{Conclusion}

In this study based upon the sample size of 26 patients receiving 90 implants in total, the following were observed:

1) 90 implants out of the 90 placed were successful with minimal crestal bone level changes at 3 years after implant surgery.

2) Drill adaptation protocol when self-taping implants are being placed in high-density bone should be considered.

\section{Conflict of Interest}

The authors declare that they have no conflict of interest.

\section{Funding}

No Funding.

\section{Compliance with Ethical Standards}

\section{Ethical approval}

All procedures performed in studies involving human participants were in accordance with the ethical standards of the institutional and/ or national research committee and with the 1964 Helsinki declaration 
and its later amendments or comparable ethical standards. The study protocol was approved by the Clinical Trials Committee of the University of Witten, Germany (32/2006, 22.05.06).

\section{Informed consent}

The informed consent was obtained from all individual participants included in the study.

\section{References}

1. Shahlaie M, Gantes B, Schulz E, Riggs M, Crigger M (2003) Bone density assessments of dental implant sites: 1. Quantitative computed tomography. Int J Oral Maxillofac Implants 18: 224-231.

2. Jemt T (1993) Implant treatment in resorbed edentulous upper jaws. Clin Oral Implants Res 4: 187-194.

3. Hitchon PW, Brenton MD, Coppes JK, From AM, Torner JC (2003) Factors affecting the pullout strength of self-drilling and self-tapping anterior cervical screws. Spine (Phila Pa 1976) 28: 9-13.

4. Spiekermann H, Jansen VK, Richter EJ (1995) A 10-year follow-up study of IMZ and TPS implants in the edentulous mandible using bar-retained overdentures. Int J Oral Maxillofac Implants 10: 231243.

5. Trisi P, Rao W (1999) Bone classification: clinical-histomorphometric comparison. Clin Oral Implants Res 10: 1-7.

6. Lekholm U, Zarb GA (1985) Patient selection and preparation. In: Brånemark $\mathrm{PI}$, Zarb GA, Albrektsson T (eds) Tissue-Integrated Prostheses: Osseointegration in Clinical Dentistry. Quintessence, Chicago, USA 199-209.

7. Norton MR, Gamble C (2001) Bone classification: an objective scale of bone density using the computerized tomography scan. Clin Oral Implants Res 12: 79-84.

8. Misch CE (1993) Density of bone: Effect on treatment planning, surgical approach, and healing. In: Misch CE (eds) Contemporary Implant Dentistry. Mosby 469-485.

9. Truhlar RS, Orenstein IH, Morris HF, Ochi S (1997) Distribution of bone quality in patients receiving endosseous dental implants. $J$ Oral Maxillofac Surg 55: 38-45.

10. Davarpanah $\mathrm{M}$, Martinez $\mathrm{H}$, Tecucianu JF, Alcoforado $\mathrm{G}$, Etienne $\mathrm{D}$, et al. (2001) The self-tapping and ICE 3i implants: a prospective 3-year multicenter evaluation. Int J Oral Maxillofac Implants 16: 52-60.

11. Olsson M, Friberg B, Nilson H, Kultje C (1995) MkIl--a modified self-tapping Brånemark implant: 3-year results of a controlled prospective pilot study. Int J Oral Maxillofac Implants 10: 15-21.

12. Ivanoff CJ, Grondahl K, Bergstrom C, Lekholm U, Branemark PI (2000) Influence of Bicortical or Monocortical Anchorage on Maxillary Implant Stability: A 15-Year Retrospective Study of Brånemark System Implants. Int J Oral Maxillofac Implants 15: 103-110.

13. Brånemark $\mathrm{Pl}$, Adell $\mathrm{R}$, Breine $\mathrm{U}$, Hansson $\mathrm{BO}$, Lindström J, et al. (1969) Intra-osseous anchorage of dental prostheses. I. Experimental studies. Scand J Plast Reconstr Surg 3: 81-100.

14. Misch CE (1990) Density of bone: effect on treatment plans, surgical approach, healing, and progressive boen loading. Int J Oral Implantol 6: 23-31.

15. Martin RB (2003) Fatigue microdamage as an essential element of bone mechanics and biology. Calcif Tissue Int 73: 101-107.

16. Fleck C, Eifler D (2003) Deformation behaviour and damage accumulation of cortical bone specimens from the equine tibia under cyclic loading. J Biomech 36: 179-189.
17. Park HS, Kwon TG (2004) Sliding mechanics with microscrew implant anchorage. Angle Orthod 74: 703-710.

18. Eriksson RA, Albrektsson T (1984) The effect of heat on bone regeneration: an experimental study in the rabbit using the bone growth chamber. J Oral Maxillofac Surg 42: 705-711.

19. Strbac GD, Giannis K, Unger E, Mittlböck M, Vasak C, et al. (2013) Drilling-and withdrawing-related thermal changes during implant site osteotomies. Clin Implant Dent Relat Res 17: 32-43.

20. Fu JH, Yeh CY, Chan HL, Tatarakis N, Leong DJ, et al. (2010) Tissue biotype and its relation to the underlying bone morphology. J Periodontol 81: 569-574.

21. Wilson DJ (1989) Ridge mapping for determination of alveolar ridge width. Int J Oral Maxillofac Implants 4: 41-43.

22. Zipprich H, Weigl P, Lange B, Lauer HC (2007) Micromovements at the implant-abutment interface: measurement, causes, and consequences. Implantologie 15: 31-46.

23. Mühlemann HR, Son S (1971) Gingival sulcus bleeding--a leading symptom in initial gingivitis. Helv Odontol Acta 15: 107-113.

24. Silness J, Loe H (1964) Periodontal Disease in Pregnancy. II. Correlation between Oral Hygiene and Periodontal Condtion. Acta Odontol Scand 22: 121-135.

25. Albrektsson T, Zarb G, Worthington P, Eriksson AR (1986) The long-term efficacy of currently used dental implants: a review and proposed criteria of success. Int J Oral Maxillofac Implants 1: 11-25.

26. Astrand $P$, Engquist $B$, Dahlgren $S$, Engquist $E$, Feldmann $H$, et al. (1999) Astra Tech and Brånemark System implants: a prospective 5-year comparative study. Results after one year. Clin Implant Dent Relat Res 1: 17-26.

27. Albrektsson T, Isidor F (1994) Consensus report of session IV. In: Lang NP, Karring $T$ (eds) Proceedings of the $1^{\text {st }}$ European workshop on periodontology. Quintessence, London 365-369.

28. Brunner E, Domhof S, Langer F (2002) Nonparametric analysis of longitudinal data in factorial experiments. J Wiley, the University of Michigan, USA.

29. Faul F, Erdfelder E, Buchner A, Lang AG (2009) Statistical power analyses using $G^{*}$ Power 3.1: tests for correlation and regression analyses. Behav Res Methods 41: 1149-1160.

30. Kline R, Hoar JE, Beck GH, Hazen R, Resnik RR, et al. (2002) A prospective multicenter clinical investigation of a bone qualitybased dental implant system. Implant Dent 11: 224-234.

31. Misch CE, Perel ML, Wang HL, Sammartino G, Galindo-Moreno P, et al. (2008) Implant success, survival, and failure: the International Congress of Oral Implantologists (ICOI) Pisa Consensus Conference. Implant Dent 17: 5-15.

32. Holm-Pedersen $P$, Lang NP, Müller F (2007) What are the longevities of teeth and oral implants? Clin Oral Implants Res 3: 15-19.

33. Friberg B, Nilson $H$, Olsson $M$, Palmquist $C$ (2002) Mk II: the selftapping Brånemark implant: 5-year results of a prospective 3-center study. Clin Oral Implants Res 8: 279-285.

34. Laurell L, Lundgren D (2011) Marginal bone level changes at dental implants after 5 years in function: a meta-analysis. Clin Implant Dent Relat Res 13: 19-28.

35. Widmark G, Friberg B, Johansson B, Sindet-Pedersen S, Taylor A (2006) Mk III: a third generation of the self-tapping Brånemark System implant, including the new Stargrip internal grip design. A 1-year prospective four-center study. Clin Implant Dent Relat Res 5: 273-279. 
36. Al-Nawas B, Wagner W, Grötz KA (2006) Insertion torque and resonance frequency analysis of dental implant systems in an anima model with loaded implants. Int J Oral Maxillofac Implants 21: 726732

37. Toyoshima T, Wagner W, Klein MO, Stender E, Wieland M, et al. (2009) Primary stability of a hybrid self-tapping implant compared to a cylindrical non-self-tapping implant with respect to drilling protocols in an ex vivo model. Clin Implant Dent Relat Res 13: 71-78.

38. Kim DR, Lim YJ, Kim MJ, Kwon HB, Kim SH (2011) Self-cutting blades and their influence on primary stability of tapered dental implants in a simulated low-density bone model: a laboratory study. Oral Surg Oral Med Oral Pathol Oral Radiol Endod 112: 573-580.

39. Rabel A, Köhler SG, Schmidt-Westhausen AM (2007) Clinical study on the primary stability of two dental implant systems with resonance frequency analysis. Clin Oral Investig 11: 257-265.

40. Yoon HG, Heo SJ, Koak JY, Kim SK, Lee SY (2011) Effect of bone quality and implant surgical technique on implant stability quotient (ISQ) value. J Adv Prosthodont 3: 10-15.

41. Kitagawa T, Tanimoto Y, Nemoto K, Aida M (2005) Influence of cortical bone quality on stress distribution in bone around dental implant. Dent Mater J 24: 219-224.

42. Quaresma SE, Cury PR, Sendyk WR, Sendyk C (2008) A finite element analysis of two different dental implants: stress distribution in the prosthesis, abutment, implant, and supporting bone. J Oral Implantol 34: 1-6.
43. Papavasiliou G, Kamposiora P, Bayne SC, Felton DA (1996) Threedimensional finite element analysis of stress-distribution around single tooth implants as a function of bony support, prosthesis type, and loading during function. J Prosthet Dent 76: 633-640.

44. Haider R, Watzek G, Plenk H Jr (1991) Histomorphometric analysis of bone healing after insertion of IMZ-1 implants independent of bone structure and drilling method (in German). Z Stomatol 88: 507-521.

45. Piattelli A, Scarano A, Balleri P, Favero GA (1998) Clinical and histologic evaluation of an active "implant periapical lesion": a case report. Int J Oral Maxillofac Implants 13: 713-716.

46. Adell R, Lekholm U, Rockler B, Brånemark PI, Lindhe J, et al. (1986) Marginal tissue reactions at osseointegrated titanium fixtures (I). A 3-year longitudinal prospective study. Int J Oral Maxillofac Surg 15: $39-52$.

47. Marković A, Mišić T, Miličić B, Calvo-Guirado JL, Aleksić Z (2013) Heat generation during implant placement in low-density bone: effect of surgical technique, insertion torque and implant macro design. Clin Oral Implants Res 24: 798-805.

48. Atieh MA, Alsabeeha NH, Payne AG, Schwass DR, Duncan WJ (2012) Insertion torque of immediate wide-diameter implants: a finite element analysis. Quintessence Int 43: e115-e126. 